\title{
Early Lessons From a Worldwide, Multicenter, Followup Study of the Recalled Articular Surface Replacement Hip System
}

\author{
Rami Madanat MD, PhD, Daniel K. Hussey BA, Gabrielle S. Donahue BA, \\ Hollis G. Potter MD, Robert Wallace MD, Charles Bragdon PhD, \\ Orhun Muratoglu PhD, Henrik Malchau MD, PhD
}

Received: 12 March 2015/Accepted: 7 July 2015/Published online: 27 August 2015

(C) The Association of Bone and Joint Surgeons (B) 2015

\begin{abstract}
Background Adverse local tissue reactions (ALTRs) around hip arthroplasties are an important reason for failure of metal-on-metal (MoM) hip implants. Little is known about capsular dehiscence patterns as ALTRs decompress from the hip into the surrounding tissue planes; these patterns may also influence the onset and severity of patient symptoms.

Questions/purposes Through a multicenter study approach, we asked: (1) Is ALTR location related to the surgical approach used for arthroplasty in patients who
\end{abstract}

One of the authors (HM) has received research support funding from Biomet (Warsaw, IN, USA), Smith \& Nephew (London, UK), Zimmer Inc (Warsaw, IN, USA), and Mako Surgical Corp (Ft Lauderdale, FL, USA). One author (OM) has received research support funding from Mako Surgical Corp. The institution of one or more of the authors (RM, DKH, GSD, CB, OM, HM) has received, during the study period, funding from DePuy Synthes (Warsaw, IN, USA).

The institution of one of the authors (HGP) has received, during the study period, funding from GE Healthcare (Waukesha, WI, USA). One of the authors (CB), or a member of his or her immediate family, has or may receive payments or benefits, during the study period, an amount of USD 10,000 to USD 100,000 from Zimmer Inc. One of the authors $(\mathrm{OM})$, or a member of his or her immediate family, has or may receive payments or benefits, during the study period, an amount of less than USD 10,000 from Corin (Cirencester, UK), Iconacy (Warsaw, IN, USA), Renovis (Redlands, CA, USA), Conformis (Burlington, MA, USA), Aston Medical (Saint-Étienne, France), Meril Healthcare (Vapi, Gujarat, India), Arthex (Naples, FL, USA), Orthopaedic Technology Group (Boston, MA, USA); USD 10,000 to USD 100,000, from Mako Surgical Corp; USD 100,000 to USD 1,000,000 from Zimmer Inc; and more than USD 1,000,000 from Biomet and Cambridge Polymer Group (Boston, MA, USA). One of the authors (HM), or a member of his or her immediate family, has or may receive payments or benefits, during the study period, an amount of USD 10,000 to USD 100,000, from Zimmer Inc, Biomet, Corin, and RSA Biomedical (Umeå, Sweden). underwent hip arthroplasty (resurfacing or THA) with a single, recalled hip arthroplasty system? (2) Do ALTR severity and location affect patient-reported outcomes in these patients? (3) Is ALTR severity different between patients who received the resurfacing version of this component (Articular Surface Replacement [ASR]) and those who received the THA implant in this system (ASR $\mathrm{XL})$ ?

Methods In a multicenter prospective study of patients who had undergone surgery with use of the ASR and ASR XL hip system (DePuy Orthopaedics, Warsaw, IN, USA),

All ICMJE Conflict of Interest Forms for authors and Clinical Orthopaedics and Related Research ${ }^{\mathbb{R}}$ editors and board members are on file with the publication and can be viewed on request. Clinical Orthopaedics and Related Research ${ }^{\mathbb{R}}$ neither advocates nor endorses the use of any treatment, drug, or device. Readers are encouraged to always seek additional information, including FDA approval status, of any drug or device before clinical use. Each author certifies that his or her institution approved the human protocol for this investigation and that all investigations were conducted in conformity with ethical principles of research, and that informed consent for participation in the study was obtained. This work was performed at Massachusetts General Hospital, Boston, MA, USA.

R. Madanat, D. K. Hussey, G. S. Donahue, C. Bragdon, O. Muratoglu, H. Malchau ( $\square)$

Harris Orthopaedic Laboratory, Massachusetts General Hospital, 55 Fruit Street, GRJ 1231, Boston, MA 02114, USA

e-mail: hmalchau@partners.org

H. G. Potter

Department of Radiology and Imaging, Hospital for Special Surgery, New York, NY, USA

R. Wallace

Sportsmed SA, Stepney, Australia 
288 patients (333 hips) from two centers had a metal artifact reduction sequence MRI of the hip performed at a mean time of 6 years postsurgery. Procedures included 166 hips $(50 \%)$ with ASR resurfacing and 167 hips (50\%) with ASR XL THA performed between 2004 and 2010. One hundred twenty-nine hips (39\%) had been operated on using a direct lateral approach and 204 using a posterior approach (61\%). The EQ-5D, Harris hip score, UCLA activity score, and visual analog scale pain score were obtained for each patient. ALTRs were classified using the Anderson ALTR grading system, and the location, synovial thickness, and diameter of the ATLRs were assessed. The relationship between ALTR location and surgical approach as well as for ALTR severity and patient-reported outcomes were evaluated, and logistic regression was used to identify predictors for moderate-to-severe ALTRs.

Results Moderate or severe ALTRs were identified in 79 hips $(24 \%)$; 41 of these hips had been operated on using the direct lateral approach and 38 using the posterior approach. In patients in whom the lateral approach was used, $83 \%$ had an anterior ALTR. Similarly, $71 \%$ of patients in the posterior approach group had posterior ALTRs. There were no differences in patient-reported outcome measures between patients with moderate-to-severe ALTRs and those with no ALTR findings on MRI ( $p>0.09$ ). Use of ASR XL was an independent risk factor for moderate-tosevere ALTRs (odds ratio, 2.8; 95\% confidence interval, 1.4-5.5 $\mathrm{p}=0.004$ ) and patients with ASR XL also had a thicker synovium (median ASR XL = 3.6 mm [1.2-10.6 $\mathrm{mm}]$, median ASR $=2.6 \mathrm{~mm}[1.2-10.7 \mathrm{~mm}], \mathrm{p}<0.001)$ and larger maximal ALTR diameter (median ASR XL = $47.6 \mathrm{~mm}$ [14-109.70 mm], median ASR = 38.4 [17.2$118.0 \mathrm{~mm}], \mathrm{p}=0.02$ ) than patients treated with ASR.

Conclusions The location of ALTRs can be predicted based on the previous surgical approach to the hip. Patients with ASR XL are more likely to develop moderate-tosevere ALTRs compared with ASR patients. An extensive range of patient-reported outcome measures may not identify all patients with ALTRs further supporting the use of MRI as a screening measure for ALTRs.

Level of Evidence Level II, therapeutic study.

\section{Introduction}

Since 1996, more than one million metal-on-metal (MoM) articular couples have been implanted in patients worldwide and it is estimated that nearly 93,000 of these procedures included articular surface replacement (ASR) acetabular components (DePuy Orthopaedics, Warsaw, IN, USA) [11, 16]. The ASR hip resurfacing system and the ASR XL for THA (ASR and ASR XL; DePuy Orthopaedics) were commercially introduced in 2004. This system including both the resurfacing and the THA versions was recalled in 2010 as a result of an unexpectedly high early revision rate [30].

One of the critical issues in arthroplasty during the last few years has been to establish an appropriate protocol for monitoring patients who have implants with MoM bearings. The goal has been to identify specific measurable parameters that can be used, alone or in combination, to screen and stratify which patients are likely to develop adverse local tissue reactions (ALTRs) and thus need either revision or close monitoring. This has proven to be challenging as we learn more about the complex interrelationships among tissue reactions, symptoms, sex of the patient, activity level, serum metal ion levels, component position, modular junctions, and component head size [16]. Further complicating the matter is that higher risk patients need to be identified before severe tissue damage occurs and to do so, these patients need to be assessed at regular intervals to minimize excessive tissue damage [21]. Additionally, the financial burden and potential patient distress need to be considered and addressed. A recent algorithm published as a consensus statement of the American Association of Hip and Knee Surgeons, the American Academy of Orthopaedic Surgeons, and The Hip Society stratifies patients into low-, moderate-, and highrisk groups based on several of the parameters mentioned [16]; however, there are still many unanswered questions such as how often we should perform imaging studies or measure systemic metal ion levels, especially if patients are completely asymptomatic. Should we be concerned about patients who are subjectively doing well? The consensus statement emphasizes that clinicians should avoid relying too heavily on any single investigative tool in the decisionmaking process, which accentuates the complexity of risk stratification.

Adverse local tissue reactions around THAs are an important reason for failure of MoM implants [18]. Previous studies have shown the prevalence of ALTRs, based on MRI, to be as high as $57 \%$ to $69 \%[5,6]$. Several studies have also shown that the survivorship of ASR XL THA is significantly poorer than for ASR resurfacing yet the reason for this is not fully understood [18, 24]. Interestingly, some studies have also reported that many ALTRs occur in asymptomatic patients [4, 31]; this is cause for concern because patients may present with symptoms only after severe collateral tissue damage has occurred, making reconstructive procedures challenging and outcomes unpredictable [21]. Also, little is known about capsular dehiscence patterns as ALTRs decompress from the hip into the surrounding tissue planes. The dehiscence patterns may also influence the onset and severity of patient symptoms. Previous incision patterns into the hip may play a role by providing a path of least resistance for increased 
intracapsular pressure. Both anterior and posterior disruption of the pseudocapsule have been reported with posterior disruption possibly more common [7].

Through a multicenter study approach, we asked: (1) Is ALTR location related to the surgical approach used for arthroplasty in patients who underwent hip arthroplasty (resurfacing or THA) with a single, recalled hip arthroplasty system? (2) Do ALTR severity and location affect patient-reported outcomes in these patients? (3) Is ALTR severity different between patients who received the resurfacing version of this component (ASR) and those who received the THA implant in this system (ASR XL)?

\section{Patients and Methods}

We performed a prospective, multicenter, followup study of the ASR hip system (ASR resurfacing and ASR XL for THA). The purpose of this multicenter study was to collect longitudinal data on a population treated with the ASR hip system that had not been revised and was undergoing regular followup. The data were collected prospectively with the aim of assessing potential predictors for various outcomes including ALTRs and patient-reported outcomes. Data were collected at Massachusetts General Hospital in Boston, MA, USA, from the various participating sites through a secure, web-based data entry and monitoring system. All patients meeting our study inclusion criteria were enrolled from 15 sites worldwide: any patient (1) with on-label use of the ASR XL or ASR component system currently implanted; (2) able to provide informed consent previously approved by institution's institutional review board or ethics committee; (3) able to return for followup annually for 5 years; and (4) able to complete the required patient-reported outcome measures. Exclusion criteria were: any patient (1) with off-label use indications for the ASR XL or ASR component system; (2) who received the ASR XL implant as a result of a hip resurfacing conversion or revision THA; and (3) with difficulty in comprehending the informed consent form for any reason.

Overall, 1258 patients (1427 hips) from 15 sites in five countries (United States, United Kingdom, South Africa, Denmark, Australia) were enrolled in the multicenter study. For our analysis, we only included data from two centers (255 patients from Center A and 33 patients from Center B) that routinely used metal artifact reduction sequence (MARS) protocol MRI as part of annual followup for ASR patients (Fig. 1). This subcohort of 288 patients (333 hips) was recruited from September 2012 to October 2014 and had an MRI of the hip performed at a mean time of 6 years postindex surgery (range, $1-10$ years). The mean age of these 288 patients was 61 years at index surgery (range, 25-95 years) and 113 (39\%) were women.
Procedures included 166 hips (50\%) with ASR resurfacing and 167 hips (50\%) with THA using the ASR XL system. One hundred twenty-nine hips (39\%) had been operated on using a direct lateral approach and 204 using a posterior approach (61\%). At both centers MRI scanners were adjusted to produce MARS. Scanning was performed with 1.5-T clinical scanners (GE Healthcare, Waukesha, WI, USA, and Siemens Healthcare, Erlangen, Germany). Sequences used in imaging were coronal, axial, and sagittal proton density or T1-weighted fast spin echo as well as coronal and axial short tau inversion recovery (STIR) sequences.

The EuroQOL five dimensions questionnaire (EQ-5D) [13, 32], the self-reported Harris hip score (HHS) [19, 26], UCLA activity score [15], and visual analog scale (VAS) pain score $(0-10)$ were obtained for all 288 patients to assess subjective health-related quality of life, hip function, activity, and pain levels, respectively. Patient-reported outcome measures were obtained at a mean $( \pm$ SD) of 3.2 \pm 6.8 months after having MRI. The outcome scores were collected using paper questionnaires and then uploaded into a web-based data entry system. The abduction angle of the acetabular components was determined from digital plain radiographs of all patients using mdesk software (RSA Biomedical, Umeå, Sweden). The mean abduction angle of the acetabular component was $43^{\circ}$ (range, $21^{\circ}-$ $63^{\circ}$ ).

Patient MR images were assessed for presence and location of ALTRs (anterior, posterior, or on both sides of the hip in axial images). ALTRs were classified as anterior or posterior based on location relative to the axis of the femoral neck in the axial MRI plane. ALTRs were also classified according to the Anderson ALTR grading system, which has the highest intra- and interobserver reliability of currently used systems $[1,28]$. Per this classification, a mild ALTR (C1) is defined as a periprosthetic soft tissue mass with no hyperintense $\mathrm{T} 2$-weighted fluid signal or a fluid-filled periprosthetic cavity less than $5 \mathrm{~cm}$ maximal diameter. A moderate ALTR (C2) is a periprosthetic soft tissue mass/fluid-filled cavity greater than or equal to $5 \mathrm{~cm}$ in diameter or $\mathrm{C} 1$ lesion with either (1) muscle atrophy or edema in any muscle other than short external rotators; or (2) bone marrow edema hyperintense on STIR sequences. Severe ALTRs (C3) include fluid-filled cavities extending through deep fascia, tendon avulsion, intermediate $\mathrm{T} 1$-weighted soft tissue cortical or marrow signal or fracture. The classification system was originally devised to correspond with the decision and urgency to treat such that $\mathrm{C} 1$ meant no immediate intervention but followup was recommended; $\mathrm{C} 2$ implied that an elective revision of the hip should be considered; and $\mathrm{C} 3$ meant an urgent need for revision surgery [1]. In addition to the Anderson ALTR grading system, synovial thickness 


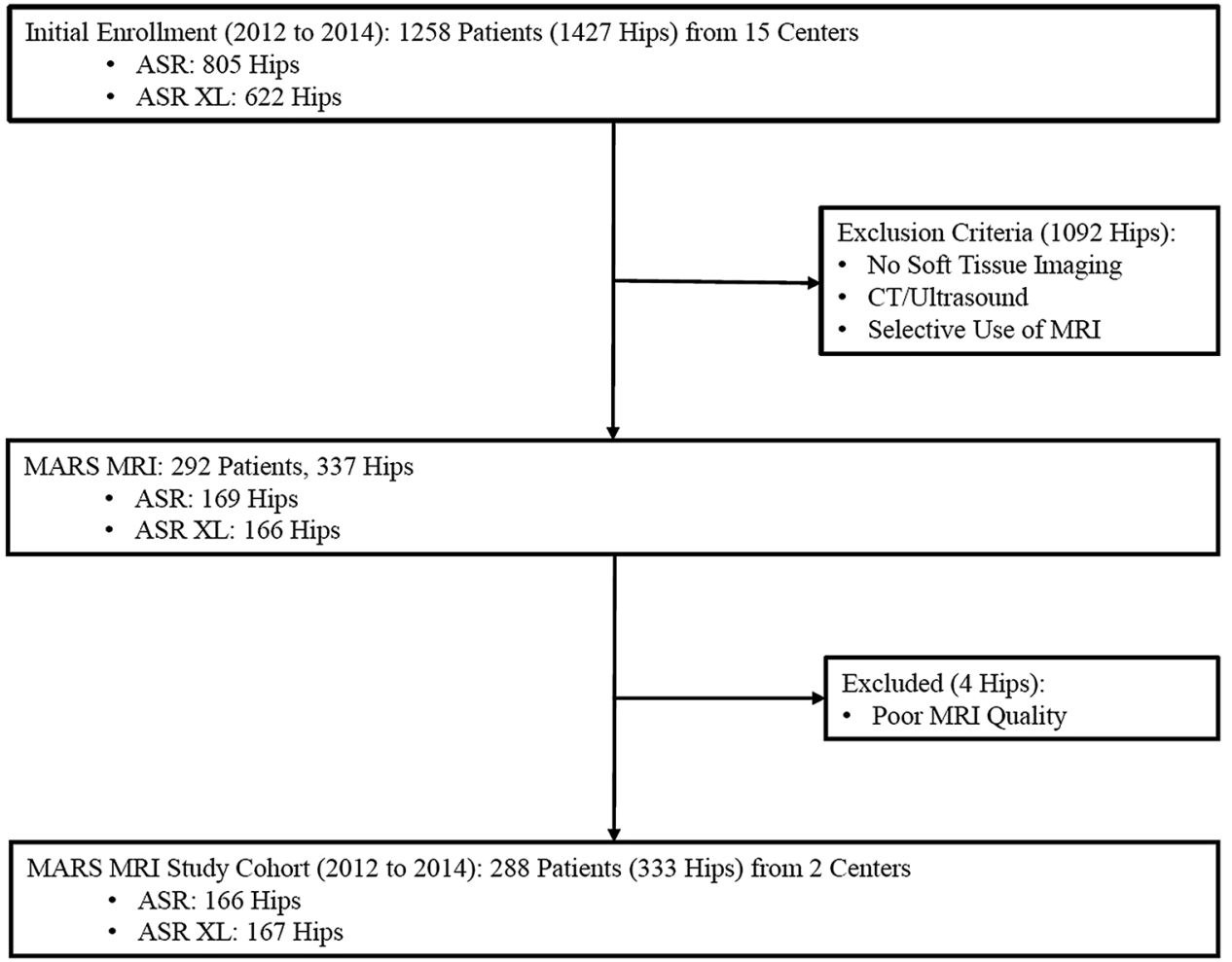

Fig. 1 Flowchart of the study cohort is shown.

and maximal diameter of ALTRs were also determined [10, 22].

All patients with extracapsular ALTRs with a maximal diameter of more than $5 \mathrm{~cm}$ were identified, which included both moderate and severe ALTRs. Mild (C1) ALTRs were excluded from the analysis of ALTR location, because these were often intracapsular or very small. MRI assessment was performed by one of the authors (RM) with 2 years of experience and validated by a musculoskeletal radiologist (HGP) with more than 10 years of experience with MARS MRI. Discrepancies were resolved by consensus. MRI assessment was blinded to all clinical and surgical patient data.

Statistical analysis was performed using the KruskalWallis test to compare patient-reported outcome measures of patients with anterior and posterior ALTRs with those of patients with no ALTRs on MRI. The Mann-Whitney U test was used to assess differences in ALTR synovial thickness and diameter between patients with procedures using ASR and those with ASR XL. After excluding 45 patients with bilateral implants, multivariate logistic regression analysis was used to determine which factors were associated with the presence of moderate and severe ALTRs. First, logistic regression models were generated to identify any predictive variables to be used in the multivariate analysis. The models were based on the independent variables of implant type (ASR or ASR XL); gender; age at the time of MRI; time from index surgery to MRI; HHS; EQ-5D score; UCLA activity score; VAS pain score; femoral head size; surgical approach (lateral or posterior); and abduction angle. Significant risk factors were used to generate multivariable logistic regression models with the dichotomous outcome variable of presence or absence of C2/C3 ALTR.

Interobserver reliability for the assessment of categorical variables (ALTR grade and location) was assessed using Cohen's kappa $(\kappa)$ and, for continuous variables (synovial thickness and maximal ALTR diameter), using Pearson's $r$. Interobserver reliability for assessment of both ALTR grade $(\kappa=0.64)$ and location $(\kappa=0.67)$ was substantial, whereas the interobserver reliability for the assessment of synovial thickness and maximal diameter was high $(r=0.91$ and $r=0.84$, respectively). A chi square test was used to assess the association between surgical approach and location of ALTR. Spearman's rank order correlation was used to assess the relationship between Anderson grade and synovial thickness. A p value $<0.05$ was considered significant. Statistical analyses were performed using SPSS (Version 17.0; IBM Corporation, Armonk, NY, USA). 

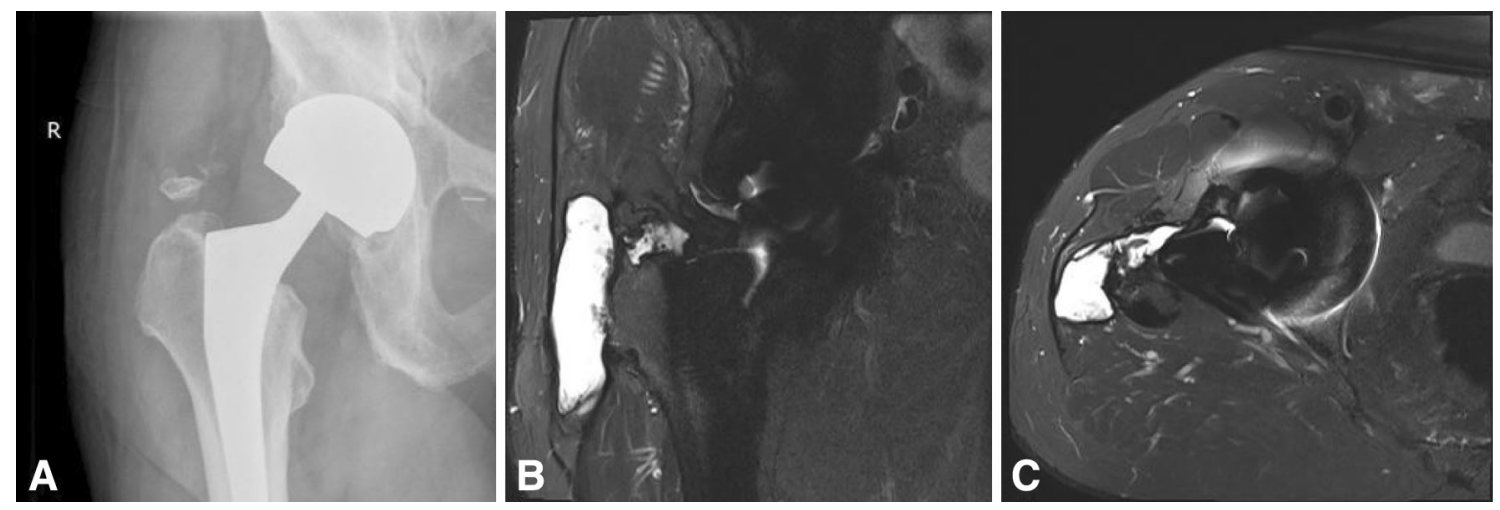

Fig. 2A-C (A) A plain radiograph shows the right hip of a 70-yearold man 9 years after undergoing ASR XL THA using a lateral approach. (B) A coronal STIR MRI image of the same hip demonstrating a large extracapsular ALTR, classified C3, in the region of the greater trochanteric bursa. (C) An axial STIR MRI image of the hip shows the anterior location and dehiscence pattern.
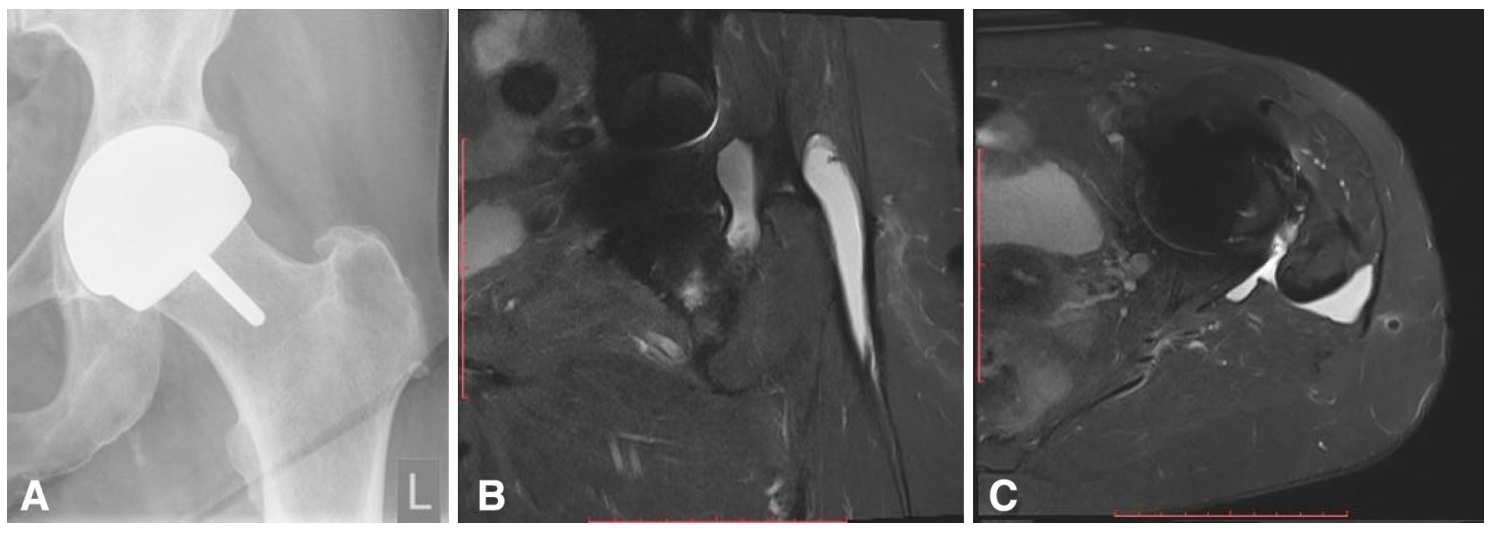

Fig. 3A-C (A) Plain radiograph of the left hip of a 64-year-old woman 10 years after ASR hip resurfacing arthroplasty performed using a posterior approach is shown. (B) A coronal STIR MRI image of the same hip demonstrating a large extracapsular ALTR, classified

\section{Results}

One hundred thirty (39\%) hips had no visible ALTRs and 124 hips (37\%) had mild (C1) ALTRs. Extracapsular ALTRs classified as severe (C3; Fig. 2) or moderate (C2; Fig. 3) were identified in 79 hips (24\%). Forty-one of the 79 hips had been operated on using the direct lateral approach (41 of 129 [32\% of hips with the lateral approach]) and the remaining 38 using the posterior approach (38 of 204 [19\% of hips with the posterior approach]). The location of ALTR corresponded with the surgical approach to the hip in the majority of cases (Fig. 4). Of patients with moderate-tosevere ALTR whose surgery was performed using a lateral approach, $83 \%$ (34 of 41) had an ALTR that was located anteriorly. Similarly, $71 \%$ (27 of 38 ) of patients with moderate-to-severe ALTR who were operated on using a posterior approach had a posterior ALTR. Ten percent (four of 41 ) of patients in the direct lateral and $21 \%$ (eight of 38 )
$\mathrm{C} 2$, in the region of the greater trochanteric bursa. (C) An axial STIR MRI image of the hip shows the posterior location and dehiscence pattern.

in the posterior approach groups had ALTRs located both anterior and posterior to the hip simultaneously (Fig. 4). Only $8 \%$ (six of 79) of patients in both the direct lateral and posterior approach groups had ALTRs located opposite to the direction of surgical approach to the hip.

Interestingly, there were no clinically relevant differences in patient-reported outcome measure scores between patient groups with mild, moderate, or severe ALTRs and those with no ALTR findings on MRI (HHS, $\mathrm{p}=0.14$; EQ$5 \mathrm{D}, \mathrm{p}=0.09$; UCLA, $\mathrm{p}=0.93$; VAS pain, $\mathrm{p}=0.20$ [Fig. 5]). Similarly, the HHS, UCLA scores, and EQ-5D scores did not differ between patients with anteriorly and posteriorly located ALTRs (Table 1). The median pain score was slightly higher $(p=0.05)$ for patients with a posterior ALTR, although likely not clinically relevant (VAS pain $=0.5$ compared with VAS pain $=1.0$ ).

Patients who had undergone THA with ASR XL had larger ALTRs (median diameter, 47.6 mm; range, 14.0-109.7 mm) 
compared with patients with ASR implants (median diameter, $38.4 \mathrm{~mm}$; range, $17.2-118.0 \mathrm{~mm} ; \mathrm{p}=0.02$ ). Similarly, patients with ASR XL also had thicker synovia (median thickness, 3.6 $\mathrm{mm}$; range, $1.2-10.6 \mathrm{~mm}$ ) compared with those of patients with ASR implants ( $2.6 \mathrm{~mm}$; range, $1.2-10.7 \mathrm{~mm} ; \mathrm{p}<0.001$ ). In the multivariate analysis, the only variable that remained

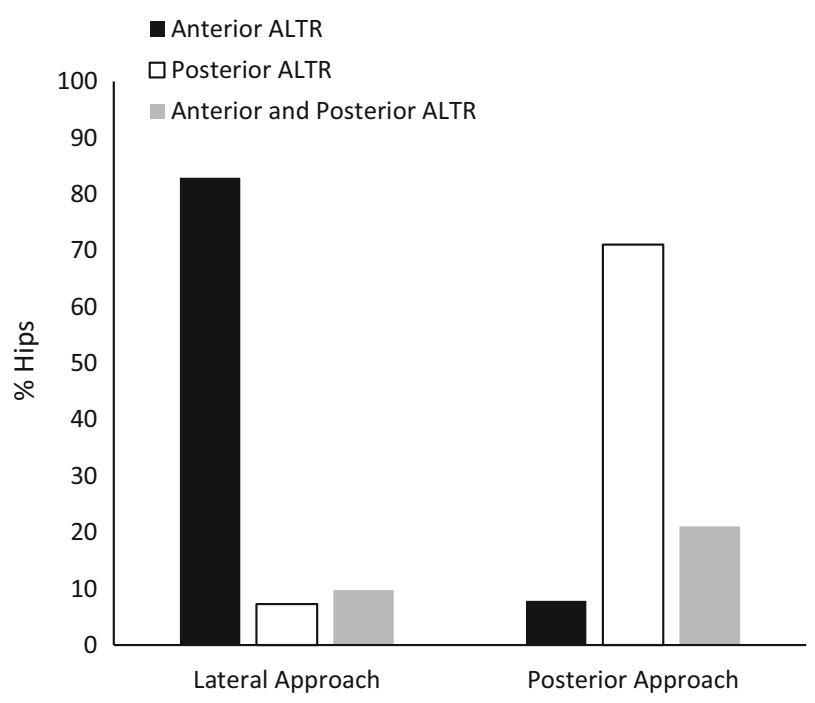

Fig. 4 The relationship between surgical approach and location of ALTR is demonstrated.

HHS

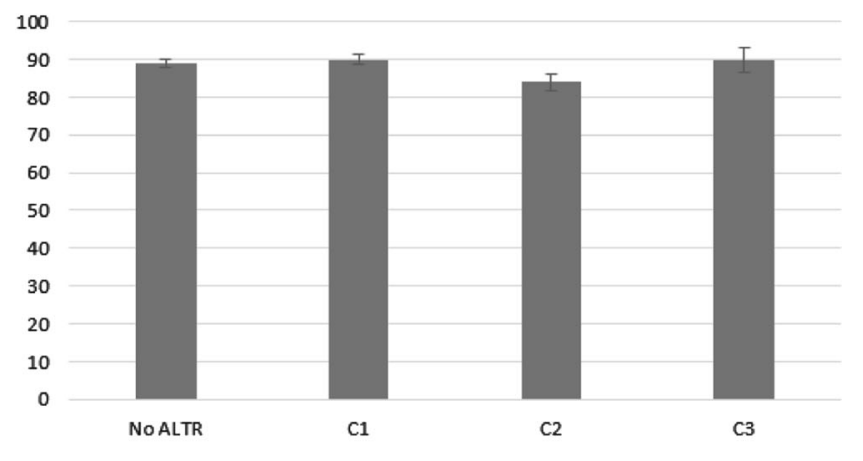

EQ-5D

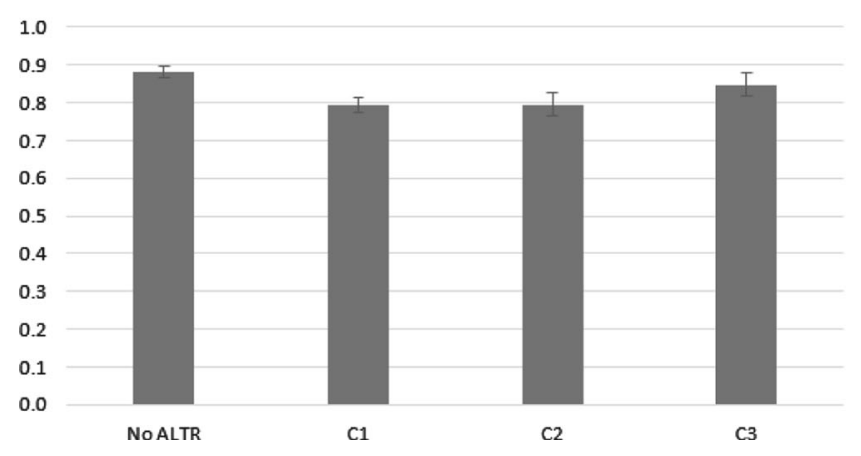

independently associated with an increased risk of moderateto-severe ALTR development was the ASR XL implant (odds ratio, 2.8; 95\% confidence interval, 1.4-5.5; $\mathrm{p}=0.004$ ). The acetabular component abduction angle, femoral component head size, or surgical approach was not associated with an increased risk of moderate-to severe ALTR. Finally, we found a significant correlation between ALTR Anderson grade and synovial thickness (Spearmans's rho $=0.762, \mathrm{p}<0.001$ ).

\section{Discussion}

There is scant literature on the relationship between the surgical approach used in arthroplasty and the location of ALTRs after hip arthroplasty using MoM implants. Furthermore, the role of subjective patient symptoms in the risk stratification process has not been defined. We showed that the location of ALTRs is related to the surgical approach used in arthroplasty. We also demonstrated that patient-reported outcomes did not differ in patients with or without ALTRs. Finally we showed that the severity of ALTRs was greater in patients with ASR XL THA.

The current study has some limitations. We were not able to include objective clinical function tests that assess ROM and abductor function because these were unavailable and not included in the study protocol. However, we

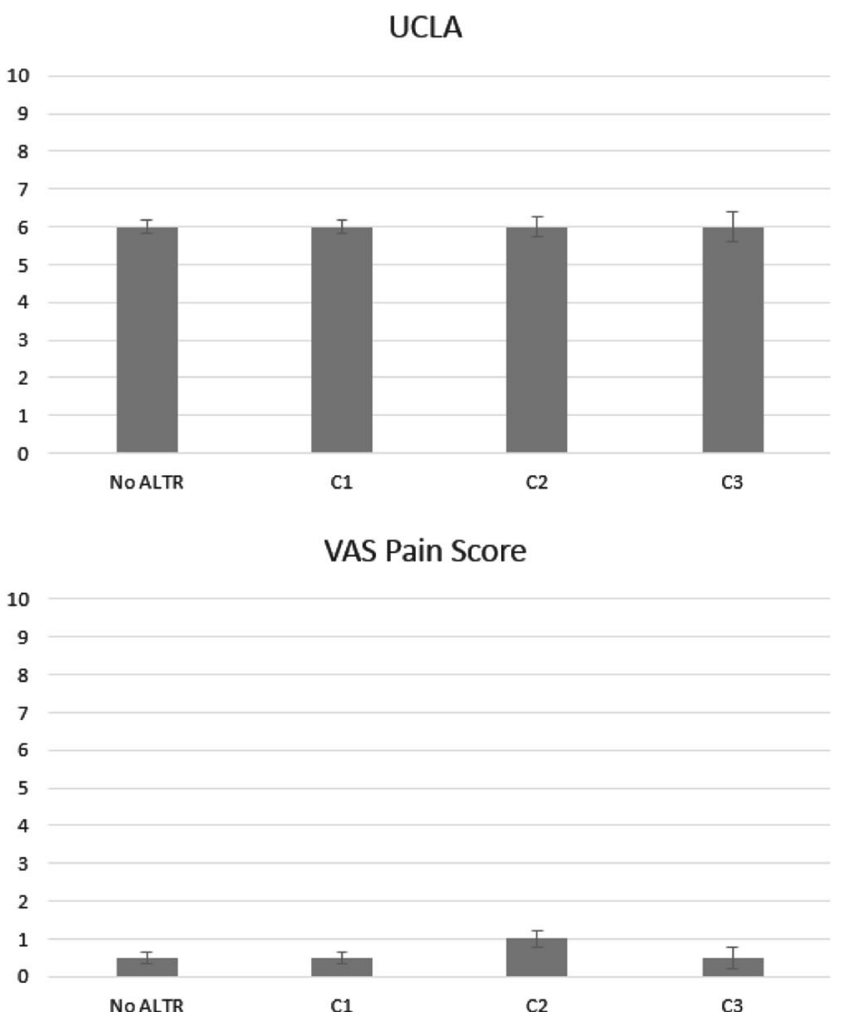

Fig. 5 Median and standard error of patient-reported outcome measure values for patients with ALTRs of increasing severity is shown. 
Table 1. Median and range of PROM values for patients with moderate and severe ALTRs based on location and compared with patients with no ALTR findings on MRI

\begin{tabular}{|c|c|c|c|c|}
\hline PROM & No ALTR & Anterior ALTR & Posterior ALTR & $\mathrm{p}$ value \\
\hline HHS & $89(35-100)$ & $90(46-100)$ & $85(18-100)$ & 0.22 \\
\hline UCLA & $6(2-10)$ & $6(3-10)$ & $6(2-10)$ & 0.99 \\
\hline EQ-5D & $0.88(0.12-1.00)$ & $1.0(0.36-1.00)$ & $0.80(0.52-1.00)$ & 0.27 \\
\hline Pain (VAS) & $0.5(0.0-10)$ & $0.5(0.0-3.5)$ & $1.0(0.0-6.5)$ & 0.05 \\
\hline
\end{tabular}

Ranges shown in parentheses; PROM = patient-reported outcome measure; ALTR = adverse local tissue reaction; HHS = Harris hip score; VAS = visual analog scale.

believe that subjective patient satisfaction, pain, and concerns related to the hip are equally important and these were thoroughly assessed using multiple, validated patientreported outcome measures included in the study protocol. The current study only included patients with the ASR hip system who had not been revised at the time of recruitment and it is possible that some patients with severe ALTRs at an early stage were not included. However, the aim of the study was to focus on the patients who had not yet been revised and were currently undergoing followup so as to better understand their risks and optimize followup strategies. Another limitation was the wide variation in the time between surgery and MRI, because no standardized protocol for when to perform MRI was used. The recently published MoM risk stratification guidelines have aimed to establish such a protocol [16], yet even with protocols, it has been acknowledged that the decision-making process for stratifying patients can be complex [3, 16]. Although we did assess the location and severity of ALTRs on MRI, we did not have intraoperative data to confirm the location and extent of tissue damage. On the other hand, MRI has high specificity in detecting pseudotumors, and both synovial thickness and ALTR size have been shown to correlate with intraoperative tissue damage and histologic aseptic lymphocyte dominated vasculitis-associated lesion (ALVAL) severity $[10,17,22]$. Finally, we were unable to include patient weight as a variable in the multivariate analysis because this information was not available for all patients in the study. On the other hand, it is noteworthy that weight is not considered a risk factor in the recent risk stratification guidelines for patients with MoM hip arthroplasty [16].

The overall prevalence of ALTRs in our study was 61\%, which is similar to the level reported in previous studies assessing MRI findings in patients with ASR implants [4, $6]$. We showed that the location of moderate and severe ALTRs with a diameter greater than $5 \mathrm{~cm}$ can be predicted in the majority of patients based on the previous surgical approach to the hip. We theorized that the location of ALTRs would be related to the initial violation of the joint capsule and surrounding soft tissues and hence the focus on the surgical approach. Fritz and coworkers [7] suggested that disruption of the pseudocapsule in progressive ALTRs usually occurs at the posterolateral attachment. This becomes intuitive in light of the current findings when we consider that most hip arthroplasties are performed from the posterior approach. Although mechanical compromise of the tissues at previous incision sites may provide a low resistance path for ALTR dehiscence, the biologic processes associated with the timing of tissue or wound healing may also play a role in ALTR progression. It is not customary to include information regarding the surgical approach used when ordering soft tissue imaging. Based on our findings, this information may be useful when screening hips with MoM implants. To our knowledge this is the first study to evaluate the relationship between ALTR location and surgical approach.

We demonstrated that patients with moderate or severe ALTRs did not have inferior patient- reported outcome measures in terms of health-related quality of life, activity level, hip function, or pain. Moreover, the location or severity of ALTRs did not affect patient-reported outcome measures. Our study results also add to the growing body of evidence that moderate and even severe ALTRs can be asymptomatic [4, 31].

The three commonly used systems for grading pseudotumors are those described by Anderson et al. [1], Matthies et al. [20], and Hauptfleisch et al. [1, 9, 20]. Of these classification systems, the Anderson grading system for ALTRs has been shown to have the highest inter- and intraobserver reliability [1, 28]. The grading system is based on the size and collateral damage associated with the ALTR. However, the Anderson ALTR grading system does not account for synovial thickness or solid components of the reaction, which have been shown to correlate with symptoms, histologic ALVAL scores, and even a higher likelihood of revision [9, 10, 22]. The other two commonly used classifications (Matthies et al. [20] and Hauptfleisch et al. [9]) do take into account the wall thickness and contents of the ALTR but are substantially inferior in both inter- and intraobserver reliability compared with the Anderson grading system for ALTR [20, 28]. 
ALTR findings on MRI do not necessarily correlate with subjective symptoms. Chang et al. [4] found no correlation between patient symptoms and severity of ALTR based on presence or size of ALTR. They did, however, find that bone marrow edema and abductor tendon tears were associated with patient pain. Another study has also shown that the prevalence of cystic pseudotumors does not differ between well-functioning and poorly functioning hip implants [8]. Several studies have also highlighted the existence of "silent" ALTRs. In a study assessing the prevalence of soft tissue pathology in hips having undergone THA with ASR XL, it was found that half the patients with the best possible Oxford hip scores had adverse reactions based on MRI assessment [31]. On the other hand, van der Weegan and colleagues showed that asymptomatic pseudotumors after MoM hip resurfacing showed little or no variation in size over 1-year followup [27]. Another study assessing longitudinal changes in ALTR findings after hip replacements with ASR in 154 hips showed that substantial pseudotumor progression occurred in only $8 \%$ of the hips and most of these had a normal baseline MRI [23]. The clinical importance and progression rate of various types of ALTR are still not fully understood. The findings from our study demonstrated that even patients with moderate and severe ALTRs generally had good-to-excellent hip function and subjective general health equal to normative values of patients with standard THA [2, 25].

Finally, we demonstrated that patients with the ASR XL implant had larger ALTRs with thicker synovia compared with patients with ASR implants. Patients who had undergone arthroplasty with ASR XL were nearly three times more likely to have moderate-to-severe ALTRs than patients with the ASR implant. This is supported by a previous study that showed a failure rate of $49 \%$ for patients with ASR XL THA compared with $25 \%$ for patients with ASR revision at 6 years [18]. Similarly, a study by Reito et al. [24] also showed that the 7-year survivorship was $51 \%$ for the ASR and only $38 \%$ for the ASR XL THA. These observed differences are likely to be attributable to reciprocating movement at the taper junction of the ASR XL THA leading to fretting corrosion described as mechanically assisted crevice corrosion [12]. Interestingly, head size was not found to be an independent predictor of moderate-to-severe ALTR in the multivariate analysis. To our knowledge this study is the largest study that has assessed both synovial thickness and ALTR Anderson grade in patients with the ASR hip system. It is also the first study to show a correlation between ALTR Anderson grade and synovial thickness.

The location of the ALTR may have several consequences because location may determine which of the surrounding tissues becomes damaged first. None of the patients included in our study had neurovascular structure involvement, which usually leads to clear symptoms in the form of swelling or neurologic deficits, subsequently prompting revision. However, it is concerning that the relatively large ALTRs did not worsen subjective outcomes in any of the multiple categories assessed in the current study. It is possible that many ALTRs do not cause symptoms until they result in a mass effect on surrounding neurovascular structures or until substantial abductor or bone damage occurs leading to instability or component loosening and associated pain or mechanical symptoms [4, 14]. It is noteworthy that some ALTRs may even initially present with superimposed periprosthetic infection [29].

Current risk stratification guidelines for patients with MoM hip arthroplasty are being updated as we learn more about the risk factors for development and progression of ALTRs. Awareness of the initial surgical approach may be useful when assessing both MR images and probably also in performing ultrasound screening of hips with MoM implants. Because dehiscence patterns generally appear to follow the surgical approach, the direct lateral approach may be associated with earlier abductor damage or detachment compared with the posterior approach and may warrant earlier intervention. There are differences in the risk of ALTR even within the recalled implant category and our study suggests that increased vigilance in the followup of patients who underwent THA with ASR XL is crucial because they are more likely to develop moderateto-severe ALTRs. Based on our study results, imaging studies should still play a key role in the risk stratification process, and lack of patient symptoms does not preclude substantial ALTRs, because even an extensive range of patient-reported outcome measures cannot identify all patients at high risk for implant failure.

Acknowledgments We thank Clinical Research Project Manager, Slav Lerner, for his help with the study and Marc Bragdon for technical assistance.

\section{References}

1. Anderson H, Toms AP, Cahir JG, Goodwin RW, Wimhurst J, Nolan JF. Grading the severity of soft tissue changes associated with metal-on-metal hip replacements: reliability of an MR grading system. Skeletal Radiol. 2011;40:303-307.

2. Bauman S, Williams D, Petruccelli D, Elliott W, de Beer J. Physical activity after total joint replacement: a cross-sectional survey. Clin J Sports Med. 2007;17:104-108.

3. Berber R, Pappas Y, Khoo M, Miles J, Carrington R, Skinner J, Hart A. A new approach to managing patients with problematic metal hip implants: the use of an internet-enhanced multidisciplinary team meeting: AAOS exhibit selection. J Bone Joint Surg Am. 2015;97:e20.

4. Chang EY, McAnally JL, Van Horne JR, Statum S, Wolfson T, Gamst A, Chung CB. Metal-on-metal total hip arthroplasty: do 
symptoms correlate with MR imaging findings? Radiology. 2012;265:848-857.

5. Chang EY, McAnally JL, Van Horne JR, Van Horne JG, Wolfson T, Gamst A, Chung CB. Relationship of plasma metal ions and clinical and imaging findings in patients with ASR XL metal-onmetal total hip replacements. J Bone Joint Surg Am. 2013;95: 2015-2020.

6. Fox CM, Bergin KM, Kelly GE, McCoy GF, Ryan AG, Quinlan JF. MRI findings following metal on metal hip arthroplasty and their relationship with metal ion levels and acetabular inclination angles. J Arthroplasty. 2014;29:1647-1652.

7. Fritz J, Lurie B, Miller TT, Potter HG. MR imaging of hip arthroplasty implants. Radiographics. 2014;34:E106-132.

8. Hart AJ, Satchithananda K, Liddle AD, Sabah SA, McRobbie D, Henckel J, Cobb JP, Skinner JA, Mitchell AW. Pseudotumors in association with well-functioning metal-on-metal hip prostheses: a case-control study using three-dimensional computed tomography and magnetic resonance imaging. J Bone Joint Surg Am. 2012;94:317-325.

9. Hauptfleisch J, Pandit H, Grammatopoulos G, Gill HS, Murray DW, Ostlere S. A MRI classification of periprosthetic soft tissue masses (pseudotumours) associated with metal-on-metal resurfacing hip arthroplasty. Skeletal Radiol. 2012;41:149-155.

10. Hayter CL, Gold SL, Koff MF, Perino G, Nawabi DH, Miller TT, Potter HG. MRI findings in painful metal-on-metal hip arthroplasty. AJR Am J Roentgenol. 2012;199:884-893.

11. Huang DC, Tatman P, Mehle S, Gioe TJ. Cumulative revision rate is higher in metal-on-metal THA than metal-on-polyethylene THA: analysis of survival in a community registry. Clin Orthop Relat Res. 2013;471:1920-1925.

12. Jacobs JJ, Cooper HJ, Urban RM, Wixson RL, Della Valle CJ. What do we know about taper corrosion in total hip arthroplasty? J Arthroplasty. 2014;29:668-669.

13. Jansson KA, Granath F. Health-related quality of life (EQ-5D) before and after orthopedic surgery. Acta Orthop. 2011;82:82-89.

14. Kawakita K, Shibanuma N, Tei K, Nishiyama T, Kuroda R, Kurosaka M. Leg edema due to a mass in the pelvis after a largediameter metal-on-metal total hip arthroplasty. J Arthroplasty. 2013;28:197 e191-194.

15. Keeney JA, Nunley RM, Wright RW, Barrack RL, Clohisy JC. Are younger patients undergoing TKAs appropriately characterized as active? Clin Orthop Relat Res. 2014;472:1210-1216.

16. Kwon YM, Lombardi AV, Jacobs JJ, Fehring TK, Lewis CG, Cabanela ME. Risk stratification algorithm for management of patients with metal-on-metal hip arthroplasty: consensus statement of the American Association of Hip and Knee Surgeons, the American Academy of Orthopaedic Surgeons, and the Hip Society. J Bone Joint Surg Am. 2014;96:e4.

17. Lainiala O, Elo P, Reito A, Pajamaki J, Puolakka T, Eskelinen A. Comparison of extracapsular pseudotumors seen in magnetic resonance imaging and in revision surgery of 167 failed metal-onmetal hip replacements. Acta Orthop. 2014;85:474-479.

18. Langton DJ, Jameson SS, Joyce TJ, Gandhi JN, Sidaginamale R, Mereddy P, Lord J, Nargol AV. Accelerating failure rate of the
ASR total hip replacement. J Bone Joint Surg Br. 2011;93:10111016.

19. Mahomed NN, Arndt DC, McGrory BJ, Harris WH. The Harris hip score: comparison of patient self-report with surgeon assessment. J Aarthroplasty. 2001;16:575-580.

20. Matthies AK, Skinner JA, Osmani H, Henckel J, Hart AJ. Pseudotumors are common in well-positioned low-wearing metal-on-metal hips. Clin Orthop Relat Res. 2012;470:18951906.

21. Munro JT, Masri BA, Duncan CP, Garbuz DS. High complication rate after revision of large-head metal-on-metal total hip arthroplasty. Clin Orthop Relat Res. 2014;472:523-528.

22. Nawabi DH, Gold S, Lyman S, Fields K, Padgett DE, Potter HG. MRI predicts ALVAL and tissue damage in metal-on-metal hip arthroplasty. Clin Orthop Relat Res. 2014;472:471-481.

23. Reito A, Elo P, Puolakka T, Pajamaki J, Nieminen J, Eskelinen A. Repeated magnetic resonance imaging in 154 hips with largediameter metal-on-metal hip replacement. Acta Orthop. 2014; 85:570-576.

24. Reito A, Puolakka T, Elo P, Pajamaki J, Eskelinen A. High prevalence of adverse reactions to metal debris in small-headed ASR hips. Clin Orthop Relat Res. 2013;471:2954-2961.

25. Rolfson O, Karrholm J, Dahlberg LE, Garellick G. Patient-reported outcomes in the Swedish Hip Arthroplasty Register: results of a nationwide prospective observational study. J Bone Joint Surg Br. 2011;93:867-875.

26. Shervin N, Dorrwachter J, Bragdon CR, Shervin D, Zurakowski D, Malchau H. Comparison of paper and computer-based questionnaire modes for measuring health outcomes in patients undergoing total hip arthroplasty. J Bone Joint Surg Am. 2011;93:285-293.

27. van der Weegen W, Brakel K, Horn RJ, Hoekstra HJ, Sijbesma T, Pilot P, Nelissen RG. Asymptomatic pseudotumours after metalon-metal hip resurfacing show little change within one year. Bone Joint J. 2013;95:1626-1631.

28. van der Weegen W, Brakel K, Horn RJ, Wullems JA, Das HP, Pilot P, Nelissen RG. Comparison of different pseudotumor grading systems in a single cohort of metal-on-metal hip arthroplasty patients. Skeletal Radiol. 2014;43:149-155.

29. Watters TS, Eward WC, Hallows RK, Dodd LG, Wellman SS, Bolognesi MP. Pseudotumor with superimposed periprosthetic infection following metal-on-metal total hip arthroplasty: a case report. J Bone Joint Surg Am. 2010;92:1666-1669.

30. Whitwell GS, Shine A, Young SK. The articular surface replacement implant recall: a United Kingdom district hospital experience. Hip Int. 2012;22:362-370.

31. Wynn-Jones H, Macnair R, Wimhurst J, Chirodian N, Derbyshire B, Toms A, Cahir J. Silent soft tissue pathology is common with a modern metal-on-metal hip arthroplasty. Acta Orthop. 2011;82:301-307.

32. Zampelis V, Ornstein E, Franzen H, Atroshi I. A simple visual analog scale for pain is as responsive as the WOMAC, the SF-36, and the EQ-5D in measuring outcomes of revision hip arthroplasty. Acta Orthop. 2014;85:128-132. 